\section{(6) OPEN ACCESS}

\title{
Lack of placental transfer of certolizumab pegol during pregnancy: results from CRIB, a prospective, postmarketing, pharmacokinetic study
}

\author{
Xavier Mariette, ${ }^{1}$ Frauke Förger, ${ }^{2}$ Bincy Abraham, ${ }^{3}$ Ann D Flynn, ${ }^{4}$ Anna Moltó, ${ }^{5}$ \\ René-Marc Flipo, ${ }^{6}$ Astrid van Tubergen, ${ }^{7}$ Laura Shaughnessy, ${ }^{8}$ Jeff Simpson, ${ }^{8}$ \\ Marie Teil ${ }^{9}$ Eric Helmer, ${ }^{10}$ Maggie Wang ${ }^{8}$ Eliza F Chakravarty ${ }^{11}$
}

\begin{abstract}
Handling editor Tore K Kvien
- Additional material is

published online only. To view please visit the journal online (http://dx.doi.org/10.1136/ annrheumdis-2017-212196).
\end{abstract}

For numbered affiliations see end of article.

Correspondence to Profesor Xavier Mariette, Université Paris-Sud, Hôpitaux Universitaires Paris-Sud, INSERM U1184, 63, rue GabrielPéri, 94270 Le Kremlin-Bicêtre, France; xavier.mariette@aphp.fr

Received 7 August 2017 Revised 22 September 2017 Accepted 1 October 2017 Published Online First 30 October 2017

\section{CrossMark}

$$
\begin{aligned}
& \text { To cite: Mariette } X \text {, } \\
& \text { Förger } F, \text { Abraham B, } \\
& \text { et al. Ann Rheum Dis }
\end{aligned}
$$$$
\text { 2018;77:228-233. }
$$

\section{ABSTRACT}

Objectives There is a need for effective and safe treatment during pregnancy in women with chronic inflammatory diseases. This study evaluated placental transfer of certolizumab pegol (CZP), an Fc-free antitumour necrosis factor drug, from CZP-treated pregnant women to their infants.

Methods CRIB was a pharmacokinetic (PK) study of women $\geq 30$ weeks pregnant receiving commercial CZP for a locally approved indication (last dose $\leq 35$ days prior to delivery). Blood samples were collected from mothers, umbilical cords and infants at delivery, and infants again at weeks 4 and 8 post-delivery. CZP plasma concentrations were measured with a highly sensitive and CZP-specific electrochemiluminescence immunoassay (lower limit of quantification $0.032 \mu \mathrm{g} /$ $\mathrm{mL})$.

Results Sixteen women entered and completed the study. Maternal CZP plasma levels at delivery were within the expected therapeutic range (median [range] $24.4[5.0-49.4] \mu \mathrm{g} / \mathrm{mL}$ ). Of the 16 infants, 2 were excluded from the per-protocol set: 1 due to missing data at birth and 1 due to implausible PK data. Of the remaining 14 infants, 13 had no quantifiable CZP levels at birth $(<0.032 \mu \mathrm{g} / \mathrm{mL})$, and 1 had a minimal CZP level of $0.042 \mu \mathrm{g} / \mathrm{mL}$ (infant/mother plasma ratio 0.0009); no infants had quantifiable CZP levels at weeks 4 and 8 . Of 16 umbilical cord samples, 1 was excluded due to missing data; $3 / 15$ had quantifiable CZP levels (maximum $0.048 \mu \mathrm{g} / \mathrm{mL}$ ).

Conclusions There was no to minimal placental transfer of CZP from mothers to infants, suggesting lack of in utero foetal exposure during the third trimester. These results support continuation of CZP treatment during pregnancy, when considered necessary. Trial registration number NCT02019602; Results.

\section{INTRODUCTION}

Most chronic inflammatory diseases (CIDs) are more prevalent in women. ${ }^{1}$ Disease onset tends to overlap with peak reproductive age, and women with CIDs are increasingly choosing to have children following diagnosis. ${ }^{2}$ Adequate disease control is crucial to ensure the best foetal and maternal health, since high disease activity is associated with an increased risk of adverse pregnancy outcomes, including miscarriage, preterm delivery and low birth weight. ${ }^{3-7}$ While disease activity may spontaneously improve during pregnancy, approximately 50\% of women with rheumatic CIDs need effective therapeutic intervention and are faced with difficult questions regarding the impact of active disease on the foetus and the safety of different therapies during pregnancy. ${ }^{8-12}$

Anti-tumour necrosis factor (anti-TNF) drugs provide an effective therapeutic option that significantly improves the signs and symptoms of CIDs. ${ }^{13}$ However, anti-TNF therapies are often discontinued after the first trimester to limit placental transfer of drug to the foetus. ${ }^{14-16}$ Active transplacental transport of immunoglobulin $G(\operatorname{IgG})$ from mother to infant is mediated by the neonatal fragment crystallisable $(\mathrm{Fc})$ receptor $(\mathrm{FcRn})$, a process that takes place mainly during the second and third trimesters of pregnancy. ${ }^{15}$ Certolizumab pegol (CZP) is a PEGylated, Fc-free anti-TNF approved for the treatment of rheumatoid arthritis (RA), axial spondyloarthritis/ankylosing spondylitis (axSpA/ AS), psoriatic arthritis (PsA), and Crohn's disease (CD). Because it lacks an IgG Fc region, unlike other anti-TNFs, CZP does not bind FcRn and is consequently not expected to undergo FcRn-mediated transfer across the placenta. ${ }^{17}$ Preclinical data and findings from two investigator-initiated studies of pregnant women treated with anti-TNFs support the hypothesis that there is minimal placental transfer of CZP in humans. ${ }^{18-21}$ However, the enzyme-linked immunosorbent assay (ELISA) used to measure CZP plasma levels in these studies was not specific for CZP, and it was not developed to measure the low CZP concentrations expected from placental transfer. Consequently, there is a need for more accurate and robust information to guide therapeutic decision making in women with CIDs regarding CZP treatment during pregnancy.

CRIB is the first industry-sponsored study designed to evaluate placental transfer of CZP from mothers to infants, by using a highly sensitive and specific assay to accurately measure the CZP plasma concentration in mothers, umbilical cords and infants at delivery, and in infants again at weeks 4 and 8 post-delivery.

\section{METHODS}

\section{Study design and patients}

CRIB (ClinicalTrials.gov, NCT02019602) was a prospective, postmarketing, multicentre, pharmacokinetic (PK) study designed to evaluate placental 


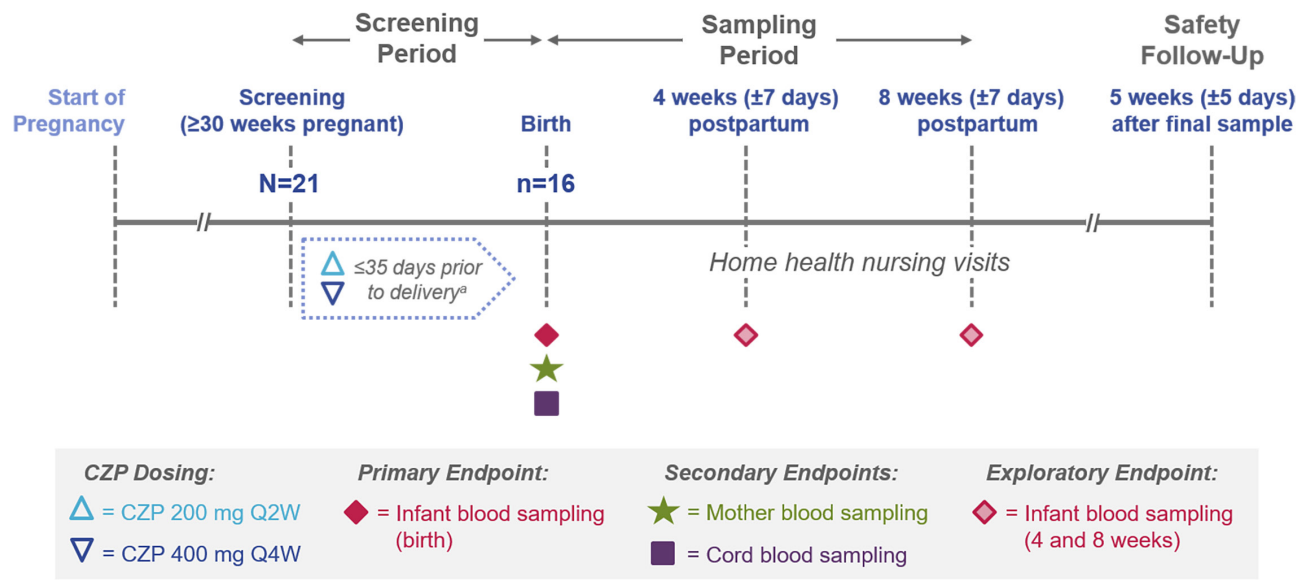

Figure 1 CRIB study design.

aLast certolizumab pegol (CZP) dose given within 35 days prior to delivery.

transfer of CZP from mothers to infants (figure 1). This study was conducted between January 2014 and November 2016 across 11 sites in France, Netherlands, Switzerland and the USA and was approved by local Institutional Review Boards. All women provided informed consent to participate and, together with the designated holder of parental rights, to enrol their infant in the study.

Eligible women were $\geq 30$ weeks pregnant at the time of informed consent. Since CRIB was a postmarketing study, all women enrolled were being treated with commercial CZP for a locally approved indication (RA, axSpA/AS, PsA, and CD), as prescribed by their treating physicians. Patients were required to receive a CZP dose within 35 days prior to delivery. The decision to continue CZP treatment during pregnancy was made by the treating physicians prior to and independently from study participation. CZP was not provided by the study sponsor.

Patients with any pregnancy-related, clinically significant abnormality noted on obstetric ultrasound or other imaging assessment, with significant laboratory abnormalities during pregnancy, or with any evidence suggesting chronic or acute uteroplacental insufficiency were ineligible to participate. Mothers who had received treatment with any biologic or any anti-TNF other than CZP during pregnancy were excluded, as were mothers who were taking or had taken any medication with a strong risk of human foetal teratogenicity during pregnancy. Also excluded were mothers with a positive or indeterminate tuberculosis (TB) test at screening, with active or latent TB infection or at high risk for TB infection.

\section{Study procedures}

Mothers received commercial CZP on either the 2-weekly dose (CZP 200 mg every 2 weeks [Q2W]) or 4-weekly dose regimen (CZP $400 \mathrm{mg}$ every 4 weeks [Q4W]), per their prescribers' discretion.

Maternal blood samples ( $\leq 4 \mathrm{~mL}$ per sample) were collected within 24 hours before or after delivery. Umbilical cord samples ( $\leq 4 \mathrm{~mL}$ per sample) were collected within 1 hour of birth. Infant blood samples ( $\leq 1.2 \mathrm{~mL}$ per sample) were collected within 24 hours after birth and at weeks 4 and 8 postpartum (figure 1). Samples collected at delivery/birth were obtained in the hospital setting, while in-home nursing visits at weeks 4 and 8 minimised the burden on mothers.

CZP concentration was measured in all plasma samples. Volume permitting, anti-CZP antibodies and total polyethylene glycol (PEG) levels (intact CZP, deconjugated PEG or other sources of PEG) were also measured. CZP and anti-CZP levels were measured at Covance Inc. (Chantilly, VA, USA). Total PEG levels were measured at Intertek Pharmaceutical Services (Manchester, UK).

CZP concentrations were measured using an electrochemiluminescence immunoassay validated in human plasma. ${ }^{22}$ The assay was developed for optimal sensitivity and specificity: CZP was captured by a TNF-coated multiarray electrode and detected with an anti-PEG antibody, prior to reading on a MESO SCALE DISCOVERY platform (MSD; Rockville, MD, USA). ${ }^{22}$ The assay is CZP-specific and $>10$ times more sensitive (lower limit of quantification [LLOQ] $0.032 \mu \mathrm{g} / \mathrm{mL}$ ) than the previous ELISA used in other CZP PK studies. ${ }^{202324}$ Anti-CZP antibodies were measured using a previously validated ELISA (samples were positive if anti-CZP antibody levels were $>2.4$ units $/ \mathrm{mL}$ ). ${ }^{24}$ Total PEG concentration was determined by nuclear magnetic resonance spectroscopy (LLOQ $2.5 \mu \mathrm{g} / \mathrm{mL}$ ).

\section{Study endpoints}

The primary endpoint was the concentration of CZP in the infants' plasma at birth. CZP and anti-CZP antibody levels in the mothers' plasma and umbilical cords were secondary endpoints. Exploratory endpoints included CZP levels in the infants' plasma at weeks 4 and 8, anti-CZP antibody levels in the infants' plasma at birth and weeks 4 and 8 , and PEG concentrations in the plasma of mothers, cords and infants.

Safety analyses included all mothers who received at least one dose of CZP, including screen failures, and infants of all mothers who entered the sampling period. Adverse events (AEs) were captured from the time of informed consent until the safety follow-up (5 weeks \pm 5 days after final sample/withdrawal) and were coded using MedDRA V.18.1.

\section{Statistical analysis}

No formal sample size calculations were performed, as no statistical hypotheses were tested. The planned sample size was 20 mother-infant pairs. All PK variables were based on observed values; no imputation was used.

\section{RESULTS}

\section{Patient disposition and baseline characteristics}

A total of 21 CZP-treated pregnant women were screened. Five women discontinued screening, one due to serious AEs (SAEs) of placental insufficiency and premature baby, and four due 


\begin{tabular}{|c|c|}
\hline Median (min, max), unless stated otherwise & Mothers $(n=16)^{a}$ \\
\hline Age, years & $31(18,40)$ \\
\hline \multicolumn{2}{|l|}{ Mother's indication for CZP treatment, $\mathrm{n}$} \\
\hline Rheumatoid arthritis & 11 \\
\hline Crohn's disease & 3 \\
\hline Psoriatic arthritis & 1 \\
\hline Axial spondyloarthritis/ankylosing spondylitis & 1 \\
\hline \multicolumn{2}{|l|}{ Delivery type, n } \\
\hline Vaginal & 14 \\
\hline Caesarean section & 2 \\
\hline Median (min, max), unless stated otherwise & Infants $(n=16)$ \\
\hline Female, $n(\%)$ & $10(62.5)$ \\
\hline Gestational age at birth, weeks & $39.9(37.7,41.7)$ \\
\hline Weight at birth, kg & $3.3(2.6,4.0)$ \\
\hline Length at birth, ${ }^{\mathrm{b}} \mathrm{cm}$ & $49.5(46.0,55.9)$ \\
\hline Head circumference at birth, ${ }^{b} \mathrm{~cm}$ & $34.5(32.5,37.0)$ \\
\hline \multicolumn{2}{|l|}{ Normal APGAR score (7 to 10$){ }_{,}^{c} n$} \\
\hline At $1 \mathrm{~min}$ & 16 \\
\hline At $5 \mathrm{~min}$ & 16 \\
\hline
\end{tabular}

${ }^{a}$ Mothers who entered the sampling period.

${ }^{b} \mathrm{n}=15$ (1 infant with missing data).

'APGAR scores range from 0 to 10 ; scores of 7 to 10 are considered normal.

APGAR, Appearance, Pulse, Grimace, Activity, Respiration; CZP, certolizumab pegol;

max, maximum; min, minimum; Q2W, every 2 weeks; Q4W, every 4 weeks.

to ineligibility. Based on preliminary PK and safety analyses, which showed consistent data for the initial mother-infant pairs enrolled in the study, a final enrolment of 16 pregnant women was deemed sufficient to assess the primary objective.

All 16 mothers who entered the sampling period completed the study (no missed visits); 15 were on CZP $200 \mathrm{mg}$ Q2W and one on CZP $400 \mathrm{mg}$ Q4W. Median time between the last CZP dose and delivery was 11 days (range 1-27 days). Baseline characteristics of all participating mothers and their infants are shown in table 1 . The gestational age and weight at birth of the 16 infants were within the expected range for healthy infants.

\section{CZP plasma concentrations}

Median CZP plasma level at delivery for all 16 participating mothers was $24.4 \mu \mathrm{g} / \mathrm{mL}$ (range $5.0-49.4 \mu \mathrm{g} / \mathrm{mL}$ ). Of the 16 umbilical cord samples, one was excluded (sample not collected). Of the 15 remaining cord samples, only three had quantifiable CZP levels $(0.035 \mu \mathrm{g} / \mathrm{mL}, 0.040 \mu \mathrm{g} / \mathrm{mL}$, and $0.048 \mu \mathrm{g} / \mathrm{mL})$; the maximum cord/mother plasma ratio for these three cords was 0.0025 .

Of the 16 infants, two were excluded from the per-protocol set: one due to missing data at birth and one due to implausible PK data. The latter infant exhibited a high plasma CZP concentration at birth $(0.485 \mu \mathrm{g} / \mathrm{mL})$, while the week 4 and week 8 sample results were below the assay LLOQ $(<0.032$ $\mu \mathrm{g} / \mathrm{mL}$ ). Using two different PK modelling approaches, there was a very low probability $(<0.1 \%)$ of an infant with this CZP concentration at birth to display levels below the LLOQ at week 4 (see online supplementary appendix for full investigation).

Of the 14 infants in the per-protocol set, 13 had no quantifiable CZP plasma levels at birth $(<0.032 \mu \mathrm{g} / \mathrm{mL})$, and one infant had a minimal CZP level at birth of $0.042 \mu \mathrm{g} / \mathrm{mL}$ (infant/mother plasma ratio 0.0009). No infants had quantifiable CZP plasma levels at week 4 (two samples missing) and week 8 (figure 2; online supplementary table 1 ). Nine mothers

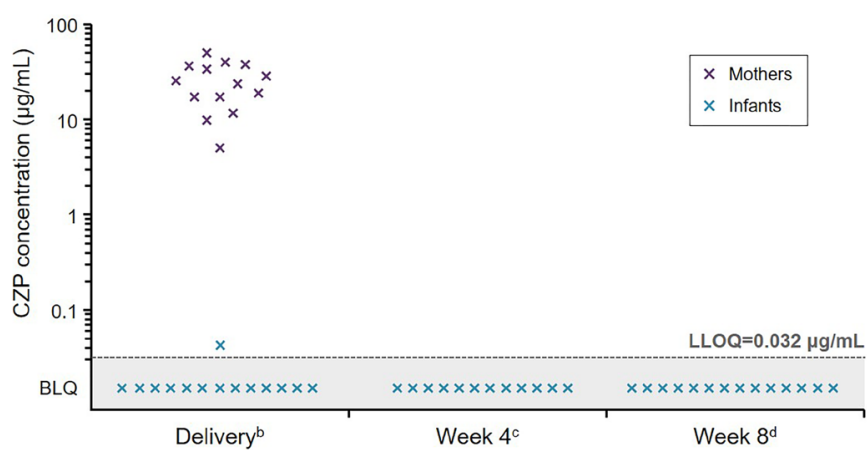

Figure 2 Plasma CZP concentrations in mothers and infants $(n=14$ mother-infant pairs ${ }^{\mathrm{a}}$ ). ${ }^{\mathrm{a}}$ Two of 16 infants were excluded from the final per-protocol set: one due to missing data at birth and one due to implausible PK data (ie, data not consistent with a paediatric CZP PK model, based on the expected range of clearance, volume of distribution and subsequent elimination half-life; see online supplementary

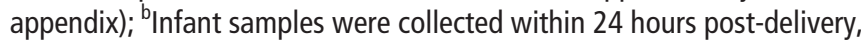
while mother samples could be collected within 24 hours before or after delivery; ${ }^{{ }} \pm 7$ days (two samples missing); ${ }^{d} \pm 7$ days. BLQ, below the LLOQ $(<0.032 \mu \mathrm{g} / \mathrm{mL})$; CZP, certolizumab pegol; LLOQ, lower limit of quantification.

continued CZP postpartum and breastfed their infants; none of these infants had quantifiable CZP plasma levels.

\section{PEG plasma concentrations}

Median PEG plasma level at delivery for all 16 mothers was 30.0 $\mu \mathrm{g} / \mathrm{mL}$ (range $10.1-59.9 \mu \mathrm{g} / \mathrm{mL}$ ). Of 15 available umbilical cord samples, 14 had no quantifiable PEG; the remaining cord had $9.8 \mu \mathrm{g} / \mathrm{mL}$ PEG (corresponding CZP level was below LLOQ). Infant data were not interpretable, due to PEG contamination of the blood collection tubes (see online supplementary appendix).

\section{Safety and immunogenicity analyses}

Safety follow-up (up to 5 weeks \pm 5 days after final sample/withdrawal) included the 21 CZP-exposed mothers screened and the 16 infants of all participating mothers. Overall, 15 mothers (71.4\%) experienced $34 \mathrm{AEs}$, and 5 infants (31.3\%) experienced 13 AEs; most AEs were mild to moderate (table 2). Two mothers reported severe AEs (arrested labour and prolonged labour), which were also classified as SAEs. All SAEs in the mothers were resolved, except for delivery of a premature baby. A severe $\mathrm{AE}$ of infection was reported in one infant, which was also an SAE (table 2). This infant had an unspecified infection indicated by elevated white blood cell count with no clinical signs. All infant SAEs were resolved. No congenital malformations were observed. No anti-CZP antibodies were detected in the mothers, umbilical cords or infants at any time point during the study.

\section{DISCUSSION}

Women diagnosed with CIDs during their reproductive years may need effective treatment to control disease activity during pregnancy ${ }^{1-7}$ However, the limited data published so far leave women and treating physicians in a difficult situation when deciding whether to continue anti-TNF therapy during pregnancy. ${ }^{8-12}$ 14-16 Although some recent treatment recommendations in rheumatology and gastroenterology state that CZP can be continued throughout pregnancy, ${ }^{25-27}$ implementation in clinical practice varies greatly across the different specialities involved in the care of pregnant women. Disease flares during pregnancy are associated with an increased risk of miscarriage, 


\begin{tabular}{|c|c|c|}
\hline n $(\%)^{a}$ & Mothers $(n=21)^{b}$ & Infants $(n=16)$ \\
\hline Any TEAEs & 15 (71.4) & $5(31.3)$ \\
\hline Mild TEAEs & $4(19.0)$ & $2(12.5)$ \\
\hline Moderate TEAEs & $9(42.9)$ & $2(12.5)$ \\
\hline Severe TEAEs & $2(9.5)$ & $1(6.3)$ \\
\hline $\begin{array}{l}\text { Discontinuation due to } \\
\text { TEAEs }\end{array}$ & $2(9.5)$ & 0 \\
\hline Drug-related TEAEs & $3(14.3)$ & $1(6.3)$ \\
\hline Serious TEAEs ${ }^{c}$ & $7(33.3)$ & $2(12.5)$ \\
\hline Deaths & 0 & 0 \\
\hline \multicolumn{3}{|c|}{ Serious TEAEs by mother-infant pair } \\
\hline SF & $\begin{array}{l}\text { Placental insufficiency } \\
\text { Premature baby }\end{array}$ & $\mathrm{N} / \mathrm{A}$ \\
\hline 1 & Arrested labour & None \\
\hline 2 & Arrested labour & None \\
\hline 3 & Prolonged labour & None \\
\hline 4 & $\begin{array}{l}\text { Gestational diabetes } \\
\text { Polyhydramnios }\end{array}$ & None \\
\hline 5 & None & $\begin{array}{l}\text { Hypoglycaemia } \\
\text { Infection }\end{array}$ \\
\hline 6 & Perineal abscess & None \\
\hline 7 & Vaginal laceration & $\begin{array}{l}\text { Macrosomia } \\
\text { Meconium in amniotic fluid }\end{array}$ \\
\hline
\end{tabular}

TEAEs were defined as any adverse event (AE) captured from the time of informed consent until the safety follow-up; bold text indicates severe TEAEs.

${ }^{a}$ Number of mothers or infants reporting at least one AE for the indicated category.

${ }^{\mathrm{b}}$ Safety set for mothers (includes five screen failures).

'Serious TEAEs were classified using the United States Food and Drug

Administration regulatory definition of serious AEs.

TEAE, treatment-emergent adverse event; SF, screen failure; N/A, not applicable.

preterm delivery and low birth weight, ${ }^{3-7}$ and may be more deleterious to neonatal outcomes than any potential risks associated with anti-TNF therapy. ${ }^{1416}$ Therefore, disease activity should be controlled through optimised medical therapy throughout pregnancy, taking into consideration the possible influence of antiTNFs on the immune response of the in utero exposed infant.

CRIB was the first industry-sponsored PK study evaluating placental transfer of a biologic, CZP, from mothers to their infants. Maternal CZP plasma concentrations were within the expected therapeutic range, ${ }^{23} 24$ confirming that all mothers in the CRIB study were adequately exposed to CZP at the time of delivery. Using the new, highly sensitive and CZP-specific assay, 13 of 14 infants had no quantifiable CZP plasma levels at birth. In the single infant with a measurable level at birth, the CZP concentration was $0.09 \%$ of the maternal CZP plasma level, which is unlikely to have any clinical relevance. At weeks 4 and 8 postpartum, there were no quantifiable CZP levels in the infants' plasma. Umbilical cord data were in agreement with the infant plasma results. AEs in the mothers were consistent with the known safety profile of CZP, and events expected during pregnancy in unexposed women with these underlying CIDs. AEs experienced by the infants did not show any patterns or clusters of events suggesting a specific safety signal in children. ${ }^{28}$

To date, two investigator-initiated studies on placental transfer of anti-TNFs have been published: one in women with CD by Mahadevan et al. (maternal, cord and infant samples collected at birth $)^{20}$ and one in women with RA and axSpA by Förger et al. (maternal and cord samples collected at birth). ${ }^{19}$ CRIB greatly expands on the available data, because it was designed to evaluate placental transfer of CZP and to further understand the PK profile of CZP at 4 and 8 weeks in the in utero exposed infant, in the event of placental transfer. Furthermore, to enhance the accuracy of CZP measurement, a new electrochemiluminescence assay was developed. ${ }^{22}$ This technology offered significantly improved specificity and sensitivity over the ELISA previously used by Mahadevan et al. and Förger et al. ${ }^{202324}$

ELISAs provide a relatively simple, high-throughput method of measuring drug concentrations in human blood. Using this type of assay, Mahadevan et al. showed low levels of placental transfer of CZP (median cord/mother percentage 3.9\%), compared to adalimumab (median cord/mother percentage 153\%) and infliximab (median cord/mother percentage 160\%). ${ }^{20}$ Förger et al. reported similar findings for CZP (maximum cord/ mother percentage 3.8\%). ${ }^{19}$ Although the ELISA used in these two studies conforms to regulatory guidelines and has been validated to measure the therapeutic range of CZP concentrations typically seen in treated adults, it was not developed to measure the low CZP concentrations expected from placental transfer (LLOQ of the ELISA $0.41 \mu \mathrm{g} / \mathrm{mL}$ ). Furthermore, the detection reagent used was an anti-human kappa light chain antibody, which is not specific for CZP and can detect other TNF-binding antibodies, such as other therapeutic anti-TNF antibodies, or naturally occurring autoantibodies to TNF $\alpha$, which can be found both in patients with CIDs and otherwise healthy individuals. ${ }^{29}$ By contrast, the new electrochemiluminescence assay used in CRIB is highly specific for CZP, since it uses a TNF-coated electrode to capture CZP and an anti-PEG antibody as the detection reagent. In addition, at an LLOQ of 0.032 $\mu \mathrm{g} / \mathrm{mL}$, the new assay is over 10 times more sensitive than the previous ELISA. ${ }^{22}$ Consequently, this assay enabled us to provide much more accurate data regarding placental transfer of CZP, which can be translated with greater confidence into evidencebased clinical practice.

One limitation of the CRIB study is the fact that the PK profile of CZP in pregnant women was not fully characterised during pregnancy, since maternal samples were collected only at delivery. It would be valuable to measure maternal CZP concentrations earlier in pregnancy and to investigate the potential impact of the loading dose (CZP $400 \mathrm{mg}$ at weeks 0,2 and 4) in women initiating CZP treatment while pregnant. Further research is needed to answer these questions.

It has been suggested that TNF $\alpha$ may play a role in the normal development of the immune system. ${ }^{30}$ However, TNF $\alpha$-deficient mice generated by gene targeting have normal secondary lymphoid organs, suggesting that TNF $\alpha$ is not necessary for lymphoid organogenesis. ${ }^{31}$ Surprisingly, these mice lack primary $\mathrm{B}$ cell follicles in the spleen, although this functional defect can be rescued by complementation of TNF $\alpha$ expression. ${ }^{31}{ }^{32}$ While rodents develop B cell follicles and germinal centres early in pregnancy, in humans, this process starts in the third trimester and continues through week 8 postpartum. ${ }^{33}$ The results of the CRIB study suggest no to minimal placental transfer of CZP during the third trimester, and the minimal level detected in one infant at birth $(<0.1 \%$ of the adult therapeutic level) can be assumed to have no effect on immune system development. Furthermore, a study in pregnant macaque monkeys examined the effect of the anti-TNF golimumab during organogenesis and the perinatal/postnatal period. Golimumab, which has an $\mathrm{Fc}$ portion and is therefore expected to actively cross the placenta, was found at high concentrations in neonatal macaques and persisted for 6 months postpartum. However, there were no significant repercussions on lymphoid organ development and immune function, suggesting once again that $\mathrm{TNF} \alpha$ may be dispensable for the immune system development during pregnancy. ${ }^{34}$ 
Humans are born with an immature immune system and have an increased risk of infection compared to adults, relying on innate immune responses and maternal antibodies transferred across the placenta and via breast milk. ${ }^{30}$ So far, few studies have examined the long-term safety of anti-TNFs in antenatally exposed children. ${ }^{35} 36$ With the exception of CZP, all approved anti-TNFs (infliximab, adalimumab, golimumab and etanercept) contain an IgG1 Fc region, which enables FcRn-mediated transport across the placenta. ${ }^{20} 30$ In a prospective study of infants born to mothers who received anti-TNFs during pregnancy, adalimumab and infliximab could be detected in infant blood until 12 months of age, due to $\mathrm{IgG}$ recycling in neonates via FcRn. ${ }^{35}$ This has raised concerns regarding the potential risk of infection and the challenges of vaccinating infants exposed to anti-TNFs in utero. By contrast, in CRIB, there were no quantifiable CZP levels in the infants' plasma at weeks 4 and 8 after birth, and AEs experienced by the infants did not suggest a specific safety signal. While these results can be considered reassuring, longterm observational studies are needed to fully characterise the safety profile of CZP in the infants of exposed mothers.

In addition to the influence of anti-TNFs on the neonatal immune system, it is also important to take into account the potential impact of intrauterine exposure earlier in pregnancy, particularly during the first trimester, before the placenta is fully formed and when organogenesis takes place. Recent systematic reviews and meta-analyses have found no association of anti-TNF exposure during the first trimester with adverse pregnancy outcomes. ${ }^{253738}$ Furthermore, evidence gathered through pharmacovigilance reporting supports the conclusion that maternal CZP exposure during the first trimester does not appear to increase the risk of adverse neonatal outcomes or major congenital malformations. ${ }^{39}$ Of note, 10 of the 14 infants in CRIB were born to mothers exposed during the first trimester.

In conclusion, our data indicate no to minimal placental transfer of CZP from mothers to infants, suggesting a lack of in utero foetal exposure during the third trimester. Combined with the evidence currently available regarding pregnancy outcomes in women exposed to CZP during the first trimester, which indicate no increased rate of major congenital malformations, ${ }^{39}$ the results of the CRIB study support the continuation of CZP treatment throughout pregnancy when considered necessary to control disease activity.

\author{
Author affiliations \\ 'Université Paris-Sud, Hôpitaux Universitaires Paris-Sud, INSERM, Le Kremlin-Bicêtre, \\ France \\ ${ }^{2}$ Inselspital, University Hospital and University of Bern, Bern, Switzerland \\ ${ }^{3}$ Houston Methodist Hospital, Houston, Texas, USA \\ ${ }^{4}$ University of Utah Health, Salt Lake City, Utah, USA \\ ${ }^{5}$ Department of Rheumatology, Hôpital Cochin, Assistance Publique - Hôpitaux de \\ Paris, INSERM, Paris, France \\ ${ }^{6}$ Centre Hospitalier Regional Universitaire de Lille, Lille, Nord-Pas-de-Calais, France \\ ${ }^{7}$ Department of Medicine, Division of Rheumatology and CAPHRI - Care and \\ Public Health Research Institute Maastricht, Maastricht University Medical Center, \\ Maastricht, Netherlands \\ ${ }^{8}$ UCB Pharma, Raleigh, North Carolina, USA \\ 'UCB Pharma, Slough, UK \\ ${ }^{10}$ UCB Pharma, Brussels, Belgium \\ 11Oklahoma Medical Research Foundation, Oklahoma City, Oklahoma, USA
}

Acknowledgements This study was funded by UCB Pharma. We are indebted to the mothers and their infants for their altruistic participation in this study. We thank the nurses and the investigator teams, the study coordination team including Samia Elyakhlifi and Lien Heinzen, UCB Pharma, and Nicole Hurst, PPD. We also acknowledge Amanda Golembesky, UCB Pharma, Raleigh, NC, USA, and Gerry Parker, UCB Pharma, Slough, UK, for their contributions; Cécile Ecoffet, PharmD, and Simone E. Auteri, MSC, UCB Pharma, Brussels, Belgium, for publication coordination; and Ricardo Milho, PhD, and Julia Bárdos, PhD, from Costello Medical, Cambridge,
UK, for medical writing and editorial assistance in preparing this manuscript for publication, based on the authors' input and direction.

Contributors XM, FF, BA, ADF, AM, R-MF, AvT, LS, JS, MT, EH, MW and EC contributed to the conception, design, execution or analysis and interpretation of the data. All authors approved the final version of the manuscript for publication.

Funding UCB Pharma sponsored the study and the development of the manuscript and reviewed the text to ensure that from a UCB Pharma perspective, the data presented in the publication are scientifically, technically and medically supportable, that they do not contain any information that has the potential to damage the intellectual property of UCB Pharma and that the publication complies with applicable laws, regulations, guidelines and good industry practice. The authors approved the final version to be published after critically revising the manuscript for important intellectual content.

Competing interests XM: grant/research support: Biogen, Pfizer, UCB Pharma; consultant for BMS, GSK, LFB, Pfizer, UCB Pharma. FF: grant/research support: UCB Pharma; speaker's fees: Mepha, Roche, UCB Pharma. BA: grant/research support: Janssen-Cilag, UCB Pharma; speaker's fees: AbbVie, American Reagent, JanssenCilag, UCB Pharma. AF: grant/research support: UCB Pharma. AM: grant/research support: MSD, AbbVie, Pfizer and UCB Pharma; consultant for: MSD, AbbVie, Pfizer, UCB Pharma. R-MF: grant/research support and consultant for: UCB Pharma. AvT: grant/research support: Pfizer, AbbVie, UCB Pharma, Janssen-Cilag, Celgene, Novartis; speaker's fees: MSD, Janssen-Cilag, Pfizer; consultant for: AbbVie, Novartis, Janssen-Cilag, Pfizer. LS: employee of UCB Pharma. JS: employee of UCB Pharma. MT: employee of UCB Pharma. EH: employee of UCB Pharma. MW: employee of UCB Pharma. EC: grant/research support: UCB Pharma.

Patient consent Detail has been removed from this case description/these case descriptions to ensure anonymity. The editors and reviewers have seen the detailed information available and are satisfied that the information backs up the case the authors are making.

Ethics approval This study was conducted between January 2014 and November 2016 across 11 sites in France, Netherlands, Switzerland and the USA and was approved by local Institutional Review Boards.

Provenance and peer review Not commissioned; externally peer reviewed.

Open Access This is an Open Access article distributed in accordance with the Creative Commons Attribution Non Commercial (CC BY-NC 4.0) license, which permits others to distribute, remix, adapt, build upon this work non-commercially, and license their derivative works on different terms, provided the original work is properly cited and the use is non-commercial. See: http://creativecommons.org/ licenses/by-nc/4.0/

(c) Article author(s) (or their employer(s) unless otherwise stated in the text of the article) 2018. All rights reserved. No commercial use is permitted unless otherwise expressly granted.

\section{REFERENCES}

1 Kavanaugh A, Cush JJ, Ahmed MS, et al. Proceedings from the American College of Rheumatology Reproductive Health Summit: the management of fertility, pregnancy, and lactation in women with autoimmune and systemic inflammatory diseases. Arthritis Care Res 2015;67:313-25.

2 Chakravarty E, Clowse ME, Pushparajah DS, et al. Family planning and pregnancy issues for women with systemic inflammatory diseases: patient and physician perspectives. BMJ Open 2014;4:e004081.

3 Bröms G, Granath F, Linder M, et al. Birth outcomes in women with inflammatory bowel disease: effects of disease activity and drug exposure. Inflamm Bowel Dis 2014;20:1091-8

4 de Man YA, Hazes JM, van der Heide $\mathrm{H}$, et al. Association of higher rheumatoid arthritis disease activity during pregnancy with lower birth weight: results of a national prospective study. Arthritis Rheum 2009;60:3196-206.

5 Jakobsson GL, Stephansson 0, Askling J, et al. Pregnancy outcomes in patients with ankylosing spondylitis: a nationwide register study. Ann Rheum Dis 2016;75:1838-42.

6 Mahadevan U, Sandborn WJ, Li DK, et al. Pregnancy outcomes in women with inflammatory bowel disease: a large community-based study from Northern California. Gastroenterology 2007;133:1106-12.

7 Nørgaard M, Larsson H, Pedersen L, et al. Rheumatoid arthritis and birth outcomes: a Danish and Swedish nationwide prevalence study. J Intern Med 2010;268:329-37.

8 Mouyis MA, Thornton CC, Williams D, et al. Pregnancy outcomes in patients with psoriatic arthritis. J Rheumato/ 2017:44:128-9.

9 Jethwa H, Lam S, Giles I. 026 Does inflammatory arthritis really improve during pregnancy? A systematic review and meta-analysis. Rheumatology 2014;53(supp 1):i40.

10 Polachek A, Li S, Polachek IS, et al. Psoriatic arthritis disease activity during pregnancy and the first-year postpartum. Semin Arthritis Rheum 2017;46:740-5. 
11 de Man YA, Dolhain RJ, van de Geijn FE, et al. Disease activity of rheumatoid arthritis during pregnancy: results from a nationwide prospective study. Arthritis Rheum 2008;59:1241-8.

12 Pedersen N, Bortoli A, Duricova D, et al. The course of inflammatory bowel disease during pregnancy and postpartum: a prospective European ECCO-EpiCom Study of 209 pregnant women. Aliment Pharmacol Ther 2013;38:501-12.

13 Tracey D, Klareskog L, Sasso EH, et al. Tumor necrosis factor antagonist mechanisms of action: a comprehensive review. Pharmacol Ther 2008;117:244-79.

14 Gisbert JP, Chaparro M. Safety of anti-TNF agents during pregnancy and breastfeeding in women with inflammatory bowel disease. Am J Gastroenterol 2013;108:1426-38

15 Hazes JM, Coulie PG, Geenen V, et al. Rheumatoid arthritis and pregnancy: evolution of disease activity and pathophysiological considerations for drug use. Rheumatology 2011;50:1955-68.

16 Hyrich KL, Verstappen SM. Biologic therapies and pregnancy: the story so far. Rheumatology 2014;53:1377-85.

17 Baker T, Kevorkian L, Nesbitt A. FRI0162 Investigation into the binding affinity of certolizumab pegol to FcRn and functional consequences for FcRn-mediated transcytosis: comparison to infliximab, adalimumab and etanercept. Ann Rheum Dis 2013;72(Suppl 3):A426.1-A426.

18 Brown D, Nesbitt A, Stephens S, et al. Lack of placental transfer and accumulation in milk of an anti-TNF PEGylated Fab' fragment in rats: P-0030. Inflammatory bowel diseases 2007;13:656

19 Förger F, Zbinden A, Villiger PM. Certolizumab treatment during late pregnancy in patients with rheumatic diseases: low drug levels in cord blood but possible risk for maternal infections. A case series of 13 patients. Joint Bone Spine 2016;83:341-3.

20 Mahadevan U, Wolf DC, Dubinsky M, et al. Placental transfer of anti-tumor necrosis factor agents in pregnant patients with inflammatory bowel disease. Clin Gastroenterol Hepatol 2013;11:286-92.

21 Porter C, Armstrong-Fisher S, Kopotsha T, et al. Certolizumab pegol does not bind the neonatal $F c$ receptor $(F C R n)$ : consequences for $F c R n$-mediated in vitro transcytosis and ex vivo human placental transfer. J Reprod Immunol 2016;116:7-12.

22 Smeraglia J, Silva JP, Jones K. Improving the sensitivity and specificity of a bioanalytical assay for the measurement of certolizumab pegol. Bioanalysis 2017;9:1217-26.

23 Lacroix BD, Parker GL. S1029 Dosing with certolizumab pegol (CZP) 200 mg every 2 weeks (Q2W) provides higher plasma trough concentrations than $400 \mathrm{mg}$ every 4 weeks (Q4W). Gastroenterology 2010;138:S-163-4.

24 Wade JR, Parker G, Kosutic G, et al. Population pharmacokinetic analysis of certolizumab pegol in patients with Crohn's disease. J Clin Pharmacol 2015;55:866-74.

25 Götestam Skorpen C, Hoeltzenbein M, Tincani A, et al. The EULAR points to consider for use of antirheumatic drugs before pregnancy, and during pregnancy and lactation. Ann Rheum Dis 2016;75:795-810.
26 Mahadevan U, Cucchiara S, Hyams JS, et al. The London Position Statement of the World Congress of Gastroenterology on Biological Therapy for IBD with the European Crohn's and Colitis Organisation: pregnancy and pediatrics. Am J Gastroenterol 2011:106:214-23

27 Flint J, Panchal S, Hurrell A, et al. BSR and BHPR guideline on prescribing drugs in pregnancy and breastfeeding-Part I: standard and biologic disease modifying antirheumatic drugs and corticosteroids. Rheumatology 2016;55:1693-7.

28 Kliegman R, Stanton B, Saint Geme J, et al. Nelson Textbook of Pediatrics. 20th ed: Elsevier Health Sciences, 2015.

29 Fomsgaard A, Svenson M, Bendtzen K. Auto-antibodies to tumour necrosis factor alpha in healthy humans and patients with inflammatory diseases and gram-negative bacterial infections. Scand J Immunol 1989;30:219-23.

30 Arsenescu R, Arsenescu V, de Villiers WJ. TNF- $\alpha$ and the development of the neonatal immune system: implications for inhibitor use in pregnancy. Am J Gastroenterol 2011;106:559-62.

31 Pasparakis M, Alexopoulou L, Episkopou V, et al. Immune and inflammatory responses in TNF alpha-deficient mice: a critical requirement for TNF alpha in the formation of primary B cell follicles, follicular dendritic cell networks and germinal centers, and in the maturation of the humoral immune response. J Exp Med 1996:184:1397-411.

32 Wen L, Shinton SA, Hardy RR, et al. Association of B-1 B cells with follicular dendritic cells in spleen. J Immunol 2005;174:6918-26.

33 Holsapple MP, West LJ, Landreth KS. Species comparison of anatomical and functional immune system development. Birth Defects Res B Dev Reprod Toxicol 2003:68:321-34

34 Martin PL, Oneda S, Treacy G. Effects of an anti-TNF-alpha monoclonal antibody, administered throughout pregnancy and lactation, on the development of the macaque immune system. Am J Reprod Immunol 2007;58:138-49.

35 Julsgaard M, Christensen LA, Gibson PR, et al. Concentrations of adalimumab and infliximab in mothers and newborns, and effects on infection. Gastroenterology 2016;151:110-9.

36 Mahadevan U, Martin C, Kane SV, et al. 437 Do infant serum levels of biologic agents at birth correlate with risk of adverse outcomes? Results from the PIANO registry. Gastroenterology 2016;150:S91-S92.

37 Komaki F, Komaki Y, Micic D, et al. Outcome of pregnancy and neonatal complications with anti-tumor necrosis factor- $\alpha$ use in females with immune mediated diseases; a systematic review and meta-analysis. J Autoimmun 2017;76:38-52.

38 Mozaffari S, Abdolghaffari AH, Nikfar S, et al. Pregnancy outcomes in women with inflammatory bowel disease following exposure to thiopurines and antitumor necrosis factor drugs: a systematic review with meta-analysis. Hum Exp Toxicol 2015;34:445-59.

39 Clowse MEB, Scheuerle AE, Chambers CD, et al. Characteristics and outcomes of prospectively reported pregnancies exposed to certolizumab pegol from a safety database. Arthritis Rheumatol 2017:69(Suppl 10(). [abstract 1309]. 